\title{
DISTANCE MAGIC CARTESIAN PRODUCTS OF GRAPHS
}

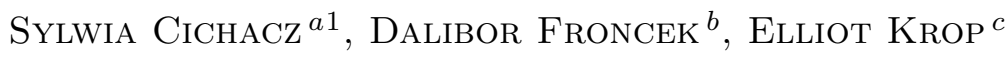 \\ AND \\ CHRISTOPHER RARIDAN $^{c}$ \\ ${ }^{a}$ AGH University of Science and Technology \\ Kraków, Poland \\ ${ }^{b}$ Department of Mathematics and Statistics \\ University of Minnesota-Duluth, USA \\ ${ }^{c}$ Department of Mathematics \\ Clayton State University, USA \\ e-mail: cichacz@agh.edu.pl \\ dfroncek@d.umn.edu \\ ElliotKrop@clayton.edu \\ ChristopherRaridan@clayton.edu
}

\begin{abstract}
A distance magic labeling of a graph $G=(V, E)$ with $|V|=n$ is a bijection $\ell: V \rightarrow\{1, \ldots, n\}$ such that the weight of every vertex $v$, computed as the sum of the labels on the vertices in the open neighborhood of $v$, is a constant.

In this paper, we show that hypercubes with dimension divisible by four are not distance magic. We also provide some positive results by proving necessary and sufficient conditions for the Cartesian product of certain complete multipartite graphs and the cycle on four vertices to be distance magic. Keywords: distance magic labeling, magic constant, sigma labeling, Cartesian product, hypercube, complete multipartite graph, cycle.
\end{abstract}

2010 Mathematics Subject Classification: 05C76, 05C78.

\section{REFERENCES}

[1] B.D. Acharya, S.B. Rao, T. Singh and V. Parameswaran, Neighborhood magic graphs, National Conference on Graph Theory, Combinatorics and Algorithms, 2004.

\footnotetext{
${ }^{1}$ Supported by National Science Centre Grant No. 2011/01/D/ST1/04104.
} 
[2] M. Anholcer and S. Cichacz, Note on distance magic graphs $G \circ C_{4}$, Graphs Combin. 31 (2015) 1117-1124. doi:10.1007/s00373-014-1453-x

[3] M. Anholcer, S. Cichacz and I. Peterin, Spectra of graphs and closed distance magic labelings, preprint, 2014.

[4] M. Anholcer, S. Cichacz, I. Peterin and A. Tepeh, Distance magic labeling and two product graphs, Graphs Combin. 31 (2015) 1125-1136. doi:10.1007/s00373-014-1455-8

[5] S. Arumugam, D. Froncek and N. Kamatchi, Distance magic graphs-a survey, J. Indones. Math. Soc., Special Edition (2011) 11-26.

[6] S. Beena, On $\Sigma$ and $\Sigma^{\prime}$ labelled graphs, Discrete Math. 309 (2009) 1783-1787. doi:10.1016/j.disc.2008.02.038

[7] S. Cichacz, Group distance magic graphs $G \times C_{4}$, Discrete Appl. Math. 177 (2014) 80-87. doi:10.1016/j.dam.2014.05.044

[8] S. Cichacz and A. Görlich, Constant sum partitions of sets of integers and distance magic graphs, preprint, 2013.

[9] R. Diestel, Graph Theory, Fourth Ed., (Vol. 173 of Graduate Texts in Mathematics, Springer, Heidelberg, 2010). doi:10.1007/978-3-642-14279-6

[10] D. Froncek, Handicap distance antimagic graphs and incomplete tournaments, AKCE Int. J. Graphs Comb. 10 (2013) 119-127.

[11] J.A. Gallian, A dynamic survey of graph labeling, Electron. J. Combin. 5 (2013) DS 6.

[12] R. Hammack, W. Imrich and S. Klavžar, Handbook of Product Graphs, Second Ed. (CRC Press, Boca Raton, FL, 2011).

[13] T. Harmuth, Über magische Quadrate und ähnliche Zahlenfiguren, Arch. Math. Phys. 66 (1881) 286-313.

[14] T. Harmuth, Über magische Rechtecke mit ungeraden Seitenzahlen, Arch. Math. Phys. 66 (1881) 413-447.

[15] M.I. Jinnah, On $\Sigma$-labelled graphs, in: B.D. Acharya and S.M. Hedge (Eds.), Technical Proceedings of Group Discussion on Graph Labeling Problems (1999) 71-77.

[16] M. Miller, C. Rodger and R. Simanjuntak, Distance magic labelings of graphs, Australas. J. Combin. 28 (2003) 305-315.

[17] S.B. Rao, Sigma graphs - a survey, in: B.D. Acharya, S. Arumugam and A. Rosa, (Eds.), Labelings of Discrete Structures and Applications (Narosa Publishing House, New Delhi, 2008) 135-140.

[18] S.B. Rao, T. Singh and V. Parameswaran, Some sigma labelled graphs I, in: S. Arumugam, B.D. Acharya and S.B. Rao, (Eds.), Graphs, Combinatorics, Algorithms and Applications (Narosa Publishing House, New Delhi, 2014) 125-133. 
[19] M.A. Seoud, A.E.I. Abdel Maqsoud and Y.I. Aldiban, New classes of graphs with and without 1-vertex magic vertex labeling, Proc. Pakistan Acad. Sci. 46 (2009) 159-174.

[20] V. Vilfred, $\Sigma$-labelled Graphs and Circulant Ggraphs, PhD Thesis (University of Kerala, Trivandrum, India, 1994).

Received 1 September 2014

Revised 19 June 2015

Accepted 19 June 2015 